\title{
Letterkunde as kulturele ekologie in Die Bergengel (Carina Stander)
}

Susan Meyer

\section{Literature as cultural ecology in Die Bergengel (Carina Stander)}

Die Bergengel (The Angel of the Mountain), with its striking nature centeredness, is characterised by poetical and lyrical use of language. This aspect is drawn into the ecocritical study of the novel in this article. Hubert Zapf's theory on literature as cultural ecology, placed within the theoretical frame of material ecocriticism, supplies the foundation for this study. An ecocritical reading of Die Bergengel leads to uncovering a counter-discourse in the novel aimed at disrupting prevalent anthropocentric views on nature and environmental issues. Narrative events reveal the agentic power of nature and its dynamic influence on human conditions; the novel challenges the long taken-for-granted dominant position of humankind. The poetic language effectively functions in highlighting the interconnections between different forms of life where previously we had seen separations, suggesting more thoughtful interpretations of human-nonhuman-relations underlying the practices of environmental violence and exploitation the novel speaks of. Where the play with language and words is so directly connected with the ecocritical discourse, literature's potential in bringing together the supposed separated spheres of culture (language) and nature becomes clear. Die Bergengel cogently voices the idea of the "reintegrative interdiscourse" which is central to Zapf's viewing of literature as cultural ecology. Keywords: Carina Stander, cultural ecology, ecocriticism, Hubert Zapf, reintegrative interdiscourse.

\section{Inleiding}

Die Bergengel, die eerste roman in Carina Stander se beplande drieluik, word beskryf as 'n subtiele vervlegting van maatskappy- en ekokritiek (Myburg). Dis 'n "enigmatiese" roman, moeilik om te kategoriseer (Steenkamp, "Bergengel"; Amid). Amid lewer positiewe kommentaar op Stander se eiesoortige interpretasie van die Bildungsroman-met magiese elemente, 'n deurlopende reismotief, klem op ouer-kindverhoudings en die gelaagdheid van die innerlike en uiterlike konflik van die jong protagonis. Die Bergengel volg op Wildvreemd (2011), Stander se debuutroman, en twee digbundels, die vloedbos sal weer vlieg (2006) en woud van nege en negentig vlerke (2009).

In my ekokritiese benadering tot die Die Bergengel is my eerste doelwit om vas te stel op watter wyse die taalgebruik in die roman benut word om die leser te beïnvloed ten opsigte van die kwessie van natuurbeskouing. Tweedens word die roman in sy hoedanigheid as 'n ekologiese krag ondersoek, oftewel as 'n roman wat 'n teengesprek ten opsigte van heersende mensgerigte beskouings van natuur- en omgewingsake tot stand bring.

Ek verskaf 'n kort oorsig oor die verhaalgebeure, verwys op bondige wyse na die ontvangs van die roman in literêre kringe en beweeg in die volgende afdeling na die ekokritiese uitgangspunte vir die studie. In die derde afdeling word die roman volgens die vasgestelde doelwitte geanaliseer.

Die verhaal se buitelyn sien só uit: Die dertienjarige Eron Verberger, die seun van die klokgieter-egpaar Alida en Gibor Verberger, vertrek saam met sy pa op 'n reis wat hom dwarsoor die wye Gabriëllië neem. Die geografiese ruimte van Gabriëllië word voorin die roman gekarteer en ook later breedvoerig beskryf; die leser word gelei om Gabriëllië as 'n reële ruimte te beleef. Die twaalf regione van die land bestaan uit stede, landbougebiede en vissersdorpies, bergstreke met groot ekologiese verskille, vlei-eilande, oerwoude en kusstroke, met "die magtige Reënrivier [wat] deur 'n kwart van die regione vloei" (16).

Op sy avontuurtog leer Eron die fyn kunste van klokgiet en manwees met sy pa as wyse leermeester. Dit is egter gou duidelik dat die rede vir Eron en Gibor se skielike vertrek uit hulle tuisdorp meer behels as 'n blote vader-en-seun-uittog. 'n Sinistere kulkunstenaar is op Eron se spoor, met moorddadige bedoelings. Boonop dreig 'n Vuurstorm om die ganse Gabriëllië te verswelg, skares mense word vermis en daar is gerugte dat die slagoffers as slawe op walvisbote gebruik word. Daar is net een persoon wat ' $n$ Vuurstorm kan stuit: die mitiese Bergengel, 'n besonderse verkose persoon wat die betrokke amp vir twintig jaar beklee voordat die vaandel aan 'n opvolger

Susan Meyer is medeprofessor in Afrikaans aan die Fakulteit Opvoedkunde, Noordwes-Universiteit, Potchefstroom. Sy is deel van die Navorsingseenheid Tale en Literatuur in Suid-Afrikaanse konteks aan die NWU.

E-pos: meyer.susan@nwu.ac.za

(iD https://orcid.org/0000-0002-7211-1530

DOl: dx.doi.org/10.17159/2309-9070/tvl.v.56i2.5179 
oorhandig word. Daar het egter reeds dertien jaar verloop sedert daar enige teken van 'n Bergengel in Gabriëllië was. Sonder die hulp van die Bergengel is dit nou Eron se taak om die Vuurstorm te blus en sy geliefdes teen die gevare van Die Uitdooftyd te beskerm. Hy word ondersteun deur mentorfigure, sy pa se broers Rauch en Korban, en moet menige toets deurstaan en struikelblok oorkom.

Die fisiese reis gaan gepaard met' $n$ reis na binne, 'n reis waarop die jong held sy vrese en skuldgevoelens in die gesig moet staar en uiteindelik moet afskud. Rauch waarsku: "[J]y gaan die kuns van selfloosheid moet bemeester, die kuns om mense ver buite jou lewe so lief te kry dat jy ook hulle wil beskerm. Jy gaan 'n honderd maal van jouself moet sterf, opstaan uit die graf en nuut begin" (151).

Kritici merk op dat Die Bergengel op verskeie vlakke gesprek voer met Deon Meyer se roman, Koors, wat in dieselfde jaar verskyn het (Steenkamp, "Bergengel"; Amid). Steenkamp sien die besonderse pa-en-seunverhouding, wat ook die goue draad deur die verhaalverloop van Koors vorm, en die genreverbuiging wat in beide romans voorkom as sterk parallelle. In Die Bergengel skep elemente van onder andere spekulatiewe fiksie, allegorie, magiese realisme, die Bildungsroman en ekokritiek die geheel. ${ }^{1}$ Koors besit eweneens elemente van spekulatiewe of bespiegelende fiksie; die jong protagonis bevind hom in 'n postapokaliptiese Suid-Afrika, 'n "sê nou maar"-situasie gebou rondom die vraag hoe om 'n samelewing weer van voor af, en uit niks, op te bou. Vanuit 'n ekokritiese perspektief beskou is die ooreenkomste duidelik; Koors se leser word, net soos dié van Die Bergengel, gekonfronteer met vrae oor die mens se reg op die aarde se hulpbronne en oor daardie fyn balans tussen die beskawing en die mens se animalistiese aard van vernielsug (Steenkamp, "Koors").

Wat literêre verdienste betref, trap Stander se roman stewige spore. Dit word bestempel as 'n betekenisvolle verruiming van die Afrikaanse letterkunde in 'n genre wat "bra beperk is", naamlik fantasie (Myburg). Steenkamp ("Bergengel") is van oordeel dat die verwewing van natuur, bo-natuur en die menslike elemente aangevul word deur " $n$ intelligensie en literêre diepte wat die roman verhef tot een met meer om die lyf as 'n blote fantasievlug". Amid se waardering is op dieselfde kwaliteite geskoei: "Die roman is fabelagtig mooi en volwasse, met groot diepte en insig." Dis 'n allegoriese fantasieverhaal wat as "uitgebreide metafoor" gelees kan word (Steenkamp, "Bergengel"); Stander beaam dat sy met Die Bergengel 'n metafoor wou skep "van 'n groeiende gees, van 'n mens se reis na jou binnelandskap—-met berge en vlerke vir skuiling".

Universele temas dra by tot die literêre diepgang van die roman. Amid verwys na die universele stryd van die ontluikende bildungsheld: Eron moet homself leer ken en vertrou te midde van onsekerheid en skuldgevoelens, hy veg om uit sy pa se skadu te kom. Daarteenoor is die Verbluffende Bluffer (oftewel Velvel Azazel), met sy oëverblindery en sy verterende drang na erkenning en mag 'n geslaagde uitbeelding van die mens se donker kant, of "skaduself". Hierdie roman verwoord diep nadenke oor die "universele aard van boosheid en broosheid in die mens se strewe na vrede en vryheid" (N. Meyer).

Die Bergengel as allegorie kan ook gelees word as besinning oor die rol van die skrywer/digter as Bergengel-figuur, meen Amid. "Soos met die profetiese Bergengel, wat in geheimhouding lewe en slegs sy verskyning maak wanneer die volk hom die meeste nodig het, word dit algaande duidelik dat daar besin word oor 'n samelewing wat gekenmerk word deur hebsug, magsug, ekonomiese verval, onverdraagsaamheid, onbeholpe leiers, sinnelose geweld en gebrek aan sosiale kohesie". Die moontlikheid dat die Bergengel inderdaad as allegoriese beeld vir die digter of profeet optree, word bevestig in die verhaalgegewe waar dit oor die anonimiteit van hierdie karakter gaan: "Die boodskap is belangriker as die Bergengel, net soos wat'n profesie groter is as 'n profeet en 'n gedig langer leef as 'n digter" (25).

Wanneer die literêre meriete van Stander se roman in besprekings daarvan ter sprake kom, word telkens teruggekeer na die element van fantasie (Myburg; N. Meyer) en die roman se bydrae tot "die afgeskeepte fantasiegenre" (Steenkamp, "Bergengel"). Die term "wêreldbou" (world building) word dikwels in fantasie en wetenskapfiksie gebruik in verband met die skep van fiktiewe wêrelde. ${ }^{2}$ Dié konsep verskil van milieubeelding in die sin dat die konstrueerder nie bloot die agtergrond waarteen 'n verhaal afspeel, skets nie, maar met toewyding en in fyn besonderhede 'n verbeelde wêreld skep wat beskik oor sy eie geografie, geskiedenis, kultuurgebruike, en so meer (Steenkamp, "Bergengel"). Steenkamp beskou die aandag aan die besonderhede van die natuurlike omgewing in Die Bergengel as die opvallendste aspek in die proses van wêreldbou: "Die skrywer skryf lewe in die geografie van die vasteland, sy uiteenlopende ekosisteme en groot verskeidenheid plant- en dierelewe in".

In die gekonstrueerde wêreld van Gabriëllië word inderdaad talle geografiese besonderhede vir elke regio betrek: weerstelsels, plantegroei, dierelewe, landvorms en ander natuurverskynsels. Daar is die seelewe van die kusdorp Skittering, die voëllewe van die waterland Eziovlei, die vulkaanklipstrande en vlambome van die tropiese 
Eiland van Ure. Die parallelle werklikheid wat hier geskep word, word uitgebeeld met besondere aandag aan die mens-omgewing-interaksie. Die naamgewing in die roman verraai reeds veel hieroor. Die meeste inwoners in die Tzurregio het vanne waarin die noue verbintenis met die natuuromgewing blyk: Storm, Moerasser, Rietbos en Wolker. Ook 'n aantal "boomryke familiename" het in die streek ontstaan, soos Vertakker, Agterstam en Peulenaar (16). 'n Algemene familienaam in hierdie streek, Verberger, het sy ontstaan te danke aan die berge wat in Tzurse volksverhale en -musiek "in verhouding gestaan het met die hemelse, aardse en onderaardse" (16). Alida Verberger, eens Alida Skemersee, kom uit 'n familie wat die Vinke genoem is, aangesien dié familie sulke voortreflike wewers was (17).

Die Bergengel vra dus uit die staanspoor om gelees en geïnterpreteer te word deur die lens van die ekokritiek, oftewel met die doel om die verhouding en interaksie tussen die mens en sy omgewing sentraal te plaas in die ontrafeling van die verhaal en sy betekenis.

Naas die sterk natuurgerigte aard van die roman word die taal- en woordgebruik beskou as 'n uitstaande kwaliteit. "Stander se talent as digter is onmiskenbaar in die liriese prosa van Die Bergengel", beweer Steenkamp ("Bergengel"). "Die Bergengel is meer as net'n roman," verklaar Amid, "dit is 'n kunswerk wat die woord tot heiligdom verhef." Hierdie spesifieke aspek van die roman sal ook in die ekokritiese bestudering daarvan betrek word. Die doel daarmee word in die volgende afdeling, saam met die teoretiese vertrekpunte vir die studie en 'n fermer belyning van die doelwitte daarvan, verantwoord en gemotiveer.

\section{Ekokritiese uitgangspunte vir die studie}

Die ekokritiek is, soos reeds gesê, die voor die hand liggende teoretiese raamwerk waarop die ontleding van die roman geskoei kan word; die ekokritiek spits hom daarop toe om letterkunde (en ander kultuurprodukte) te ondersoek aan die hand van die wyse waarop dit die verhouding tussen die mens en al die organismes van die natuurlike wêreld wat hom omring, uitdruk. Die tweede sin in die roman, met die beskrywing van Gabriëllië as 'n wêreld "waar lokomotiewe nog nie tonnels deur die berge oopgefluit het of rokerige longe oor die valleie en weivelde uitgehoes het nie" (13), vra reeds dat die ekokritiek in die ondersoek betrek sal word en bring ook Lawrence Buell se definisie daarvan ter sprake. Buell (11), een van die baanbrekers vir die ekokritiek, definieer hierdie dissipline as die bestudering van die verhouding tussen letterkunde en omgewing wat onderneem word in 'n gesindheid van toewyding aan omgewingskundige praktyke of -gebruike. Buell, Heise en Thornber beklemtoon, in hulle meer volledige definisie van die ekokritiek, die etiese element daarvan:

Ecocriticism is a cross-disciplinary initiative that aims to explore the environmental dimensions of literature and other creative media in a spirit of environmental concern not limited to any one method or commitment. Ecocriticism begins from the conviction that the arts of imagination and the study thereof - by virtue of their grasp of the power of word, story, and image to reinforce, enliven, and direct environmental concern-can contribute significantly to the understanding of environmental problems [...]. Ecocriticism holds that environmental phenomena must be comprehended, and that today's burgeoning array of environmental concerns must be addressed qualitatively as well as quantitatively. (Buell, Heise en Thornber 418)

Gelees deur die lens van die ekokritiek, skuif 'n spesifieke aspek van Die Bergengel op die voorgrond: die roman ondersoek die verhouding tussen tegnologiese vooruitgang, hebsug, magsug en die verwoestende impak hiervan op die natuurlike omgewing. Steenkamp ("Bergengel") vat hierdie kwessies op kernagtige wyse raak:

Die pre-industriële Gabriëllië staan op die drumpel van 'n industriële revolusie. Nuut-aangelegde treinspore deurkruis die voorheen ongerepte landskap en lei tot die migrasie van velddiere (41);'n korrupte bewind stook met geweld die vure van 'vooruitgang'. Die heersende regiohoofde, in sameswering met die ryk en magtige walvismagnate, loods' $\mathrm{n}$ veldtog om die selfonderhoudende agrariese gemeenskappe van Gabriëllië stelselmatig uit te wis en te vervang met onvolhoubare industrie ter ondersteuning van die winsgewende walvisjagbedryf."

Die inwoners van Gabriëllië, verblind deur wanhoop en die belofte van goudwater (die walvistraan wat hulle vasteland skynbaar tot'n wêreldmag sal verhef), sien die verwoesting as'n uitkoms, "n skoonbrand, 'n nuutbegin" (Bergengel 163). Eron luister met ontsteltenis hoe 'n houtkapper wat hy in Slagtingstrand raakloop die Vuurstorm wat die stad Barbel in puin gelê het, afmaak as "hoop vir die land":

Die nuwe Regiohoof, die vrygewige Strasius, [het] die versukkeldes uit hulle ou krotjies verwyder, die bourommel verbrand en sy stad herbou tot iets nuttigs. Fabrieke en goeie geriewe, daardie klas van ding-alles gebou met die fortuine van die walvishandel wat nou die streek instroom. Veral aan die kus waar die walvisbote aandoen is daar baie bouwerk 
aan die gang. Van die ander Regiohoofde is glo ook deel van die plan om van Gabriëllië'n wêreldmag te maak. (132)

Aangesien ekokritiek beskou word as 'n sambreelterm vir 'n hele spektrum van literêr-teoretiese benaderings met ' $n$ "earth centred approach" ten opsigte van die bestudering van die menslike en die niemenslike (Childs en Fowler 65), is die kwessie van 'n spesifieke en gepaste teoretiese grondslag van besondere belang in 'n ekokritiese studie. 'n Punt van kritiek wat in die ontstaansjare van die ekokritiek dikwels geopper is, is die gebrek aan 'n behoorlike metodologie en teoretiese basis (Gifford 15), terwyl die interdissiplinêre aard van ekokritiek as die belangriker aspek voorgehou is. Sedert die middel 1990's word daar egter gereeld ekokritiese navorsing met 'n sterk teoretiese basis gepubliseer as bewys dat die ekokritiek wel toenemend gesofistikeerd vertoon (Fiedorczuk 11).

Hubert Zapf se boek Literature as Cultural Ecology: Sustainable Texts (2016) is een van die onlangse publikasies met groot waarde vir die ekokritikus wat na teoreties gefundeerde werkwyses soek. Die beskouing van letterkunde as kulturele ekologie bied, volgens Salovaara (222), 'n sinvolle teoretiese instrument en 'n stewige metodologiese raamwerk in die ekokritiese bestudering van tekste.

Zapf (Literature 3) definieer kulturele ekologie op bondige wyse as die bestudering van en teorievorming oor die interaksie en lewende onderlinge verband tussen kultuur en natuur. Daar word gefokus op die funksie van letterkunde as ekologiese beginsel of energie binne die groter sisteem van kulturele diskoerse (27). Die sogenaamde "ekologiese" funksie van letterkunde manifesteer op verskeie wyses. Letterkunde is 'n gebied van voortdurende, kreatiewe vernuwing van taal, persepsies, kommunikasie en verbeelding. Hierdie herstrukturerende en selforganiserende beginsels van letterkunde herinner Zapf aan die ekologiese prosesse met behulp waarvan alle lewe op selforganiserende wyse voortbestaan ("The state of ecocriticism and the function of literature as cultural ecology" 56). Een van die wyses waarop die ekologiese funksie van letterkunde manifesteer, lê in die beskouing van letterkunde as klankbord vir verskuilde probleme, tekorte en wanbalanse in die groter kulturele werklikheid (Zapf, "State" 56). In Amid se bespreking van Die Bergengel word die vinger netjies op hierdie funksie van die roman gelê waar verwys word na die besinning oor 'n samelewing "gekenmerk deur hebsug, magsug, ekonomiese verval, onverdraagsaamheid, onbeholpe leiers, sinnelose geweld en gebrek aan sosiale kohesie".

Tweedens behels die ekologiese funksie van letterkunde dat dit help met die afbreek van geslote denkpatrone onderliggend aan dogmatiese wêreldbeskouings en om eksklusiewe aansprake op die waarheid te vervang met ' $n$ verskeidenheid van perspektiewe en veelvuldige interpretasiemoontlikhede (Zapf, "State" 56). Die beskouing van letterkunde as ekologiese krag in die groter kultuursisteem lei tot die beklemtoning van die potensiaal daarvan om bepaalde werklikheidsaspekte wat deur konvensionele denke uitgesluit is van die kulturele werklikheidsgeheel daarmee te herenig. Letterkunde sou dan deel wees van wat Zapf ("State" 64) die diskoers oor herintegrasie (reintegrative interdiscourse) noem. Hy illustreer die konsep van die "geskeide werklikheid" met verwysing na voorbeelde van die verskillende samelewingsfere wat ontstaan deur ekonomiese differensiasie, die openbare en die private rolle van die self, die bewuste en die onbewuste en ook-grondliggend aan verskeie manifesteringsvorms van hierdie skeidingsbeginsel-kultuur en natuur (64-5).

In Die Bergengel mag die aanwending van taal, as deel van die literêre skeppingsproses en ook van kulturele aktiwiteit, 'n bydrae lewer om dogmatiese natuurbeskouings en eksklusief menslike aansprake op eienaarskap van die natuurlike omgewing af te breek. Dus is die eerste doel van hierdie artikel, soos reeds genoem, om die aard van die taalgebruik, die affektiewe trefkrag daarvan en die funksie van die taalspel spesifiek ten opsigte van mens- en natuurbeelding te ondersoek. Met ander woorde, die funksie van taalaanwending, uit die sfeer van kulturele aktiwiteit, word binne konteks van die ekokritiese diskoers in hierdie roman beskou. Die vraag wat as vertrekpunt dien, is: Op watter wyse dien taalgebruik die diskoers oor omgewingskwessies deur die beïnvloeding ten opsigte van natuurbeskouings? Oftewel: Hoe realiseer die integrering van die konvensioneel geskeide kultuuren natuurwêrelde in hierdie roman, en word Die Bergengel deel van wat Zapf die diskoers oor herintegrasie noem?

Ek het ook reeds verwys na die tweede doel vir hierdie studie, naamlik om uit die denkraamwerk van letterkunde as kulturele ekologie nog 'n teoretiese beginsel te identifiseer en te benut in die ontleding van Die Bergengel. Daar word gefokus op die roman as 'n ekologiese krag - "ecological force" (Zapf, Literature 27) - die tipe letterkunde wat oor die potensiaal beskik om teéngesprekke tot stand te bring, "challenging current unsustainable societal and economic practices, operating as a medium of radical civilizational critique" (Zapf, Literature 28). Die aard van dié teengesprek in Die Bergengel word ondersoek, die aandag word toegespits op die wyse waarop 'n koersverandering téén vaste denkpatrone in oopgeskryf word; hoedat antroposentriese beskouings-en daarmee saam onvolhoubare ekonomiese praktyke-uitgedaag word. 
Die teoretiese raamwerk waarop Zapf die sterkste steun, is dié van die materiële ekokritiek en die insigte van Jane Bennett, Serenella Iovino en Serpil Oppermann aangaande niemenslike liggaamlikheid en magte van beïnvloeding. ${ }^{3}$ Die nuwe materialisme is 'n teoretiese terrein wat verskeie dissiplines dien, onder andere dié van die natuurwetenskappe, filosofie en literatuurteorie en -kritiek, en waarbinne herbesinning plaasvind oor die materialiteit waaruit ons liggame en die natuurlike wêreld gemaak is. ${ }^{3}$ Binne die teoretiese raamwerk van die nuwe materialisme word natuurelemente nie as passiewe sosiale konstruksies beskou nie, maar eerder as vorms van bemiddelende krag wat interaksie met en verandering of beïnvloeding van ander elemente teweegbring, ook van die mens (Alaimo en Hekman 7). Oppermann ("Feminist ecocriticism: the new ecofeminist settlement" 72) stel dit só:

The new materialists perceive nature as an active, signifying force; an agent in its own terms [...]. Being thus liberated from its previous conceptualizations as a blank, silent resource for the exploits of culture [...] nature is discussed as a significant participatory force field in the entanglement of meaning and matter.

Die idee dat materie 'n mag van beïnvloeding ("agentic power") uitoefen, ook oor die mens, lei tot Bennett (xvi) se gevolgtrekking dat menslike magte en beïnvloedingsvermoë weerklank vind in dié van niemenslike bestaansvorme, sodat daar 'n teenvoeter bestaan vir die antroposentriese idee dat die mens in beheer van die wêreld is. By die begrippe materie en materialiteit word menslike en niemenslike liggaamlikheid ingesluit, en lewende sowel as nielewende stowwe, substansies of kragte (Oppermann, "Feminist ecocriticism" 7l). Hierdie konsepte is dus nie geskoei op die eng dualisme van lewend/nielewend, menslik/niemenslik nie. Coole en Frost (9) vat die sleutelinsigte van die nuwe materialisme soos volg saam:

Conceiving matter no longer as simply passive or inert, disturbs the conventional idea that agents are exclusively human and possess the cognitive abilities, intentionality, and freedom to make autonomous decisions and the corollary presumption that humans have the right or ability to master nature. Instead, the human species is being relocated within a natural environment whose material forces themselves manifest certain agentic capacities.

In noue aansluiting by bogenoemde gedagtes kan die teorieë van die objekgeoriënteerde ontologie ("object oriented ontology") gelees word, spesifiek betreffende die ommekering van aanvaarde subjek- en objekrolle en -posisies. ${ }^{4}$ Morton (165) verduidelik die objekgeoriënteerde ontologie se beskouing dat die objek 'n sentrale posisie kry; die stel van die mens (subjek) se bestaan bó die van niemenslike objekte word verwerp. Met hierdie standpunt word antroposentrisme sterk teengestaan en word direkte skakeling met die teorieë van die nuwe materialisme duidelik.

In die volgende afdeling word die taalgebruik in Die Bergengel onder die soeklig geplaas en gefokus op die rol van taal, as kultuurmedium, in die uithef van die natuur en omgewingskwessies. Die doel is om vas te stel op watter wyse die taal- en woordspel in diens van die diskoers oor natuur-/omgewingskwessies staan deur die bydrae daarvan tot die uitdaag van eksklusief menslike aansprake op eienaarskap van die natuurlike omgewing. Hieruit sal die hereniging van die apart gewaande wêrelde van die woord (kultuur) en die natuur blyk, en sal die roman se bydrae tot die diskoers oor herintegrasie duidelik word.

\section{Die Bergengel as ekologiese krag: nuwe denke oor mens en natuur}

Die taalgebruik in Die Bergengel word gekenmerk deur die meesleurende poëtiese aard daarvan. 'n Eerste opvallende aspek is dat natuurtaal en poëtiese natuurbeelde in die uitbeelding van mense gebruik word. Alida Verberger se swangerskap bring iets dromerigs uit haar te voorskyn, "iets herfserigs" (18) Eron is 'n seuntjie met 'n "eekhoringgesiggie" en donker rugdonsies (19); hy het "vuurvliegieklein" pinkienaels en "wangkuiltjies die vorm van waterdruppels" (20).

Eron se waarnemings word dikwels poëties getint deur beeldspraak swaar belaai met metaforiek uit die natuurwerreld. Die reis wat hy saam met sy vader onderneem, neem hulle bo-oor verysde berge. 'n Yspunt teen 'n berghelling waaraan Eron vashou, breek af en hy vrees hy gaan val, maar skielik staan Gibor agter hom om hulp te bied, "'n vaste dop oor 'n skilpad" (61). Gibor druk sy seun se gesig teen sy bors vas voordat hulle saam aanskuif, "sy pa 'n skulp rondom hom" (62). Die Gubbrivier wat die stad Barbel omarm, se brug is gebou met gebuigde latte, "tonnelagtig, soos die ribbekas van 'n walvis" (69).

Eron neem dikwels 'n natuurelement waar in die mense wat hy op sy uitgebreide reis teëkom: kleuters hang "soos vlermuisies" aan 'n ma se sye (70), 'n groep meisies is "lawwe, luidrugtige mossies" (73) en daar word na 'n paar ou vroue langs die rivier buite Barbel verwys as "dié ry knopperige, klamp sampioene wat op 'n omgevalle 
boomstomp gesit het" (77). Op hierdie moeilike tog vind hy dikwels krag in die beeld van sy moeder; hy herroep haar gestalte soos sy aangestap gekom het op die dag van hulle vertrek, "haar regop nek, 'n trotse kraanvoël" (100).

Deur die beskrywing van die natuurelement wat Eron in mense vind en deur die poëtiese beelde wat deur sy waarneming daarvan opgetower word, word'n kwessie uitgehef wat sentraal staan in die posthumanistiese denke wat die materiële ekokritiek onderlê. Dit behels die herbesinning oor die konsep wat Wolfe (Critical Environments: Postmodern Theory and the Pragmatics of the "Outside" 42) die "human tout court" noem, oftewel "rethinking the conceptual frameworks within which we have defined human subjectivity, agency, identity and self, acknowledging the permeable boundaries of species in the natural-cultural continuum, and recognizing the profound interconnections between different forms of life in the composite world where previously we had seen separations." Wanneer die waarneming en beskrywing van die menslike deurtrek is van verwysings na niemenslike eienskappe, soos in Die Bergengel gebeur, word 'n belangrike doelwit in posthumanistiese denke bereik, naamlik die ongeldigverklaring van die standpunt van menslike uitsonderlikheid.

Hiermee word die weg gebaan vir die tersydestelling van dogmatiese idees oor die mens-natuurdigotomie en word 'n denksfeer betree waar dit sin maak om Wolfe se uitdrukking "humans and other animals" te gebruik, soos in die boek Before the Law: Humans and Other Animals in a Biopolitical Frame gebeur. Eron beland in Barbel byna-byna onder die invloed van Bluffer, die kulkunstenaar, en probeer desperaat wegkom-"hy was 'n rot wat wou vlug voor 'n glimmende reptiel" (Bergengel 83). Ná 'n woeste vlugtog deur die brandende stad duik hy in die rivier en probeer sy roetbesmeerde lyf was, "sy vingers soos glippende visse" oor sy oksels en skouers. In die wyse waarop Eron homself waarneem, naamlik in terme van die niemenslike, word veel sigbaar van die opvatting van die mens wat Wolfe (Before the Law 34) huldig, naamlik "joined together, in a dynamic co-evolutionary spiral with other biological species with whom we share the planet". Die metaforiese taalgebruik in hierdie roman dien 'n beskouing van die mens wat nie meer op die eng dualisme van menslik/niemenslik berus nie; die poëtiese beelding lig hierdie beskouing uit en brand dit skerp in die leser se bewussyn vas. Selfs die mens se innerlike wêreld word verbeeld in terme van 'n verknooptheid met die natuur: Eron ontdek "dat skuld 'n kragtige stroom is wat klippe kan verteer" (Bergengel 88); kwelvrae klou "soos 'n wurgslang om sy keel" (89).

Terwyl bepaalde idees oor die gebruikswaarde van en menslike gesag oor die natuur sterk in sekere verhaalgebeure teenwoordig is, dien die liriese aard van die prosa in die roman kragtig ter bewusmaking van téénvrae betreffende mensgesentreerde houdings en natuurbeskouings. Deur die rykheid van die taal word eer aan die natuur gebring, die intrinsieke waarde daarvan word erken en die diversiteit daarvan besing. Eron se verwondering oor die natuur, reeds as 'n kind, en sy sintuiglike verering word duidelik juis in die poëtiese terme waarmee dit verwoord word: "Hy het paddavissies dopgehou wat uit hul jellieomhulsels glip en wriemel in die stroom agter die huis waar sy blaarbote dryf; [...] deur die biesies waar die blougroen naaldekokers flits tot waar die stroom uitmond en sy blaarbote ingesluk is deur die koue oseaan" (21). Die grootste respek blyk ook uit Gibor se poëtiese beskouing van natuurskepping versus menslike skepping: "Geboue is versteende gedagtes. Berge is heiligdomme wat aanhou groei" (59).

Op sekere punte op sy reis word Eron deur uitputting en vrae oor die sin van hierdie oorweldigende onderneming oorval. Hy vind perspektief en emosionele ewewig terug in die versekering van 'n groter plan van orde en betekenis rondom hom:

'n Rooiborsie wat onder 'n brug van boomwortels vlieg: onwerklik rooi, asof sy inwendig bloei. [...] Die spore van 'n wildsbok wat 'n roetekaart in die riviersand teken - die varser spore van 'n vos kort op sy hakke. In die verte het 'n lammervanger met gepunte vlerke op 'n krans afgepyl, gevolg deur'n jammerlike gekerm. Die pieke [...] heidepers.

Die gerusstellende effek van hierdie natuurtekens op Eron se gemoed word uitgehef deur die liriek en die rykheid van die taal. Op 'n jeugdige ouderdom het beelde uit die natuur reeds vir Eron lesse ingehou, byvoorbeeld dat 'n dier se spoor sy angs kan verraai (59). Die impak wat hierdie beelde op sy jong gemoed gehad het, word onderstreep deur beeldryke taal wanneer Eron sulke lesse herroep. "'Spore is die stemme van diere,' het Gibor gesê. 'Elke spoor vertel 'n storie. 'n Mens moet jou eie voetspoor ken." (60)

Hierdie verwysings na die natuurkennis en ook die diep respek wat Gibor aan Eron oordra, versterk die vrae wat die mens se seggingskrag oor die natuurlike omgewing uitdaag. Die idee van menslike besitreg word saam met dié van menslike uitsonderlikheid bevraagteken.

Die gebeure in Die Bergengel vloei voort uit tegnologiese vooruitgang in Gabriellië en word gedryf deur menslike hebsug en magsug. Die roman wentel, op eerste verhaalvlak, om die gewetenlose uitbuiting van die visbedryf, 
winsbejag wat berus op die uitbuiting van hulpbronne, en om natuuruitwissing ter wille van onvolhoubare industrieë, alles in die naam van "vooruitgang". Op 'n ander vlak word daar egter 'n helder teengesprek op die been gebring-een wat die sienings onderliggend aan hierdie praktyke beveg en wat verband hou met die ontkieming van alternatiewe persepsies oor die plek van die mens in die omgewing. In ryk, poëtiese taal word die stryd aangepak ter afdwing van die aandag aan die deurdringbare grense tussen spesies in die menslikeniemenslike kontinuum en aan die erkenning van die diepgaande onderlinge verbondenheid tussen verskillende vorms van lewe in die saamgestelde bestaansgeheel. In Die Bergengel wil die gebeure op die primêre verhaalvlak die magsmisbruik van die mens uitspel; die taal wil teenstand bied daartéén-om te praat, met besondere estetiese krag, oor die besondersheid, broosheid en onvervangbaarheid van die natuur.

Zapf se beskouing van letterkunde as kulturele ekologie, oftewel vernuwende krag, word relevant en taal word hier funksioneel betrek. Die ekologiese funksie van letterkunde word duidelik wanneer die moontlikhede van die affektiewe reaksie van die leser op die taalgebruik in Die Bergengel verreken word. Zapf (Literature 32) verduidelik, omtrent die krag van die gevoelskomponent in die estetiese teks:

The particular aesthetic force of an Emily Dickinson poem can awaken in the reader an affective response that initiates intellectual investigations into the validity of long taken-for-granted "culture-nature binaries". [...] Understanding the coexistence of humanity with the nonhuman world as a "mutual relationship" instead of seeing the nonhuman merely in 'utilitarian' ways is one particular function of sustainable texts.

Taal en die besondere affektiewe funksie daarvan staan sentraal in die uithef van die deesdae bykans vergete belang van die natuur in Die Bergengel. Die mens word, by wyse van kragtige beeldspraak, herinner aan die dwaasheid van omgewingsverwoesting, aan die noodsaak om "jou eie voetspoor (te) ken" (87) en om dáárdie impak te oordink.

Nie slegs op taalvlak nie, maar ook op inhoudsvlak word die ekologiese krag van die roman duidelik in die oopdwing van nuwe denkpatrone oor mens en natuur. Die teengesprek, wat as duidelike beskawingskritiek gemik is teen onvolhoubare samelewings- en ekonomiese praktyke, vind op die tweede verhaalvlak plaas en is geskoei op die gegewe van die verweefde lot van die mens en die niemenslike in die uitbuiting daarvan. Die bloederige handel van die walvistraanbaronne het nie net'n effek op die walvisbevolking nie, maar eis ook menslike slagoffers in die vorm van slawe, diegene wat ontvoer word tydens Vuurstorms om die walvisskepe te beman (94).

Die verweefdheid van menslike en niemenslike eienskappe in die uitbeelding van menslike karakters, waarop tevore reeds gewys is, word verder versterk deur die parallel wat tussen menslike en niemenslike kinders getrek word. Alida offer 'n handgemaakte poppie wat haar doodgebore dogtertjie verteenwoordig aan die see en "toe sy die serp oopvou, het die kind verander in 'n bloupers seester wat stadig, stadig tuimelswem, al dieper in die baarmoeder van die oseaan" (18). Tydens Eron se besoek aan die Eiland van die Ure ontmoet hy Olga, wat desperaat probeer om 'n gestrande walviskalf veilig terug aan die see en sy moeder te besorg. Olga is die ma van die "verlore seun" en kulkunstenaar, Velvel Azazel, en van 'n dogter met wie sy kontak verloor het. Haar worsteling met die walviskalf word gedryf deur die voorspelling dat "sy haar seun aan die wêreld gaan afstaan, maar haar dogter sal terugvind as sy 'n ander ma help om haar verlore kind te vind" (186). Hierdie belofte-'n kind in ruil vir 'n kind—dui op 'n verweefdheid, 'n komplekse verhouding tussen die mens en sy natuurlike omgewing.

Die materiële ekokritiek en spesifiek die idee van materie- "human and nonhuman bodies, and organic and inorganic substance and forces" - as 'n aktiewe krag (Oppermann, "Feminist ecocriticism" 7l), bring insig in die mens-natuurverhoudings wat in Die Bergengel uitgebeeld word. Hier is natuurelemente veel meer as 'n passiewe agtergrond vir die menslike drama. Daar word gereeld iets duidelik van die beskouing omtrent die interaktiewe en handelende aard van die natuur, en spesifiek as 'n krag van beïnvloeding van ander elemente, ook van die mens (Alaimo en Hekman 7).

Gibor word in sy karakter, identiteit en in die daaglikse omgang met sy ambag deur die natuur beïnvloed. Die berge waardeur Gabriellië ingeperk word en die impak daarvan op die inwoners se lewens, is nie slegs teenwoordig in Gibor se van (Verberger) nie. Hierdie berge is ook 'n vaste deel van sy verwysingsraamwerk en vind weerklank in die krag van sy persoonlikheid. "Jou pa sou oor 'n duisend berge reis om jou lewe te spaar", vertel Eron se ma vir hom (93).

Gibor word beskryf as 'n aardse mens met 'n skaapveljas en "duifgrys hare" (90), gevolg deur "die reuk van metaal, hout en vuur" (23). Wanneer Gibor hout op die vuur gooi, sien Eron saam met hom hoe die reuk en die kleur van die vlamme met elke houtsoort verander. Gibor glo dat kennis van hout en die wyer natuur jou in die kader van die superieure plaas. "As jy die taal van hout verstaan, sal jy ook [...] die taal van engele verstaan" (40). 
Hy wys sy seun om rigting te vind uit die skadukant van die maan en die posisie van die sterre; wanneer hy oor dié dinge praat, is sy stem vol ontsag, "asof dit'n aandgebed is" (41).

Gibor het geen twyfel dat die natuur met die mens kommunikeer nie. Eron wil by geleentheid weet of ape kan praat; Gibor antwoord sonder huiwering: "Jou ma het jou mos geleer dat alles kan praat, Eron, selfs klippe" (47). Eron se vraag is gemotiveer deur 'n insident op 'n vismark, waar iemand 'n aap aan 'n tou gehad het, 'n kermende bondel. Hier het Eron iets van 'n intieme vervlegting van die menslike en dierlike bestaan beleef, dit was asof sy eie diepste aard aan hom bekend geword het in die oomblikke toe hy sy veronderstelde superieure posisie ontruim en op die vlak van die dier gekom het. "Ek het myself in die oë van die groter aap gesien, Pa. Ek was bang vir myself, omdat ek skielik vir niks bang was nie" (48).

Dis Gibor se natuurgesentreerde ingesteldheid wat'n goeie klokmaker van hom maak. Hy het fyn insig in die wyse waarop die klank van die klok bepaal word deur die soort metaal waarvan dit gemaak is, want: "Elke metaal praat 'n eie taal" (54). Sy ambag as klokmaker bring hom intiem in kontak met' $n$ hele aantal natuurelemente, as't ware luisterend na die voorskrif van elke element vir daardie "regte toonhoogte en timbre" (52). Vir elke gietstuk word 'n buiteklok uit leemklip gemaak en met 'n mengsel van strooi en perdemis bedek om droog te raak. 'n Kleibeeld word gevorm volgens die binnekant van die klok wat gegiet moet word en nadat die son dit gedroog het, word byewas oor die klok gegiet en 'n laag klei aan die buitekant gesmeer. Holtes word aan die rante geboor waaruit die warm byewas kan smelt wanneer dit in die vuurput is. Nadat die klok uit die vuurput herwin is, word vloeiwarm metaal in die opening tussen die kleilae gegiet.

Die wyse waarop Gibor die natuurelemente hanteer en vereer waarmee hy op kreatiewe vlak besig is, soos dit in die roman beskryf word $(44,52)$, skep die indruk dat die nielewende se stem dié van die mens oorheers. Hierdie gedagte sluit aan by een van die kernbeginsels wat die materiële ekokritiek uit die denkwêreld van die objekgeoriënteerde ontologie benut, naamlik die opheffing van die mens (subjek) se sentrale posisie, ter beklemtoning van 'n verbintenis van respek met die niemenslike wat ontdaan is van die rol as objek (Morton 165).

Die klokmaker in Die Bergengel beleef dat die interaktiewe betrokkenheid van die natuur en die aard van die gawes daarvan, konkreet waarneembaar in terme van die beskikbaarheid en gehalte van die natuurprodukte, die gehalte van klok as eindproduk bepaal. Dit is een van die belangrikste lesse omtrent die ambag wat Eron by sy pa leer. Hy word ook uiteindelik beloon met 'n eerste, voltooide klok uit 'n proses waartydens stap vir stap, en op eerbiedige wyse, met natuurgawes omgegaan is. Hierdie eerste klok is vir Eron meer van 'n natuurproduk as die produk van sy eie hande: "O, die ekstase toe sy heel eerste klok soos'n ryp, swart saad tussen die gebreekte doppe lê!" (53)

Die ommekeer van die konvensionele subjek-objekverhouding tydens mens-natuurinteraksie is 'n belangrike element in die teengesprek wat in die roman gevoer word ter bevraagtekening van die mens se sogenaamd superieure seggenskap oor die benutting van die gawes van die natuur. Dit herinner ons aan die perspektief op die mens wat Oppermann ("From Material to Posthuman Ecocriticism: Hybridity, Stories, Natures" 276) vanuit posthumanistiese konteks bied: "The shift away from the conjectural singularity of the human agency is not a wholesale rejection of humanism (or the human), but a critical reframing aimed to dissolve the accompanying impulse of exploiting the coexisting sphere of the nonhuman."

'n Lewensles met behulp waarvan Gibor vir Eron toerus en weerbaar maak vir die oomblik wanneer hyself nie meer as gids vir sy seun kan optree nie — soos inderdaad op die reis gebeur—is die volgende: "Jy moet die lewe met jou eie verstand en al honderd jou sintuie ontdek" (19). Met hierdie aanmoediging om sintuiglik te leef, open hy sy seun se oë vir die invloed en gesag waarmee die natuur die mens se lewe in sekere situasies rig. Wanneer Eron van sy pa geskei word in die brandende stad Barbel, skep die rivierdelta vir hom 'n alternatiewe roete terug huis toe, weg van die bekende handelspaaie, om sy agtervolger vry te spring. Hy het die rivierpad na die Tzur-regio waar sy tuisdorp is, nog nooit gevolg nie; dié "waterpad" word egter 'n aktiewe rolspeler wat uitkoms bied uit lewensgevaar. Die delta word 'n stem wat vir Eron lei: "Elke keer voordat hy 'n vertakking van die delta moes neem, moes hy eers stilstaan en die natuur lees soos sy pa hom geleer het. Kyk na die posisie van die son. Voel die westewind vanaf die see [...]. Ruik die lug [...], die landskap met varings en mos wat aan die skadukante van die bome groei. Kyk, kyk, kyk" (88).

Die rol van aktiewe, kragtige beïnvloeding wat hier aan die landskap toegeken word, strook met die nuwe materialisme se uitgangspunt dat die nielewende 'n mag van beïnvloeding uitoefen, ook oor die sfeer van menslike bestaan. 'n Teenvoeter word dus gebied vir die antroposentriese idee dat die mens in beheer van sy wêreld is. Eron steun dikwels en op verskeie wyses op die rigtingwysers wat die natuur bied en wat hy interpreteer as 
boodskappe van waarskuwing of gerusstelling. Die "weerlose nes" van 'n lyster en die spore van 'n vos op die hakke van 'n wildsbok maak hom akuut bewus van sy eie kwesbaarheid, hulle is "tekens" en "voorbodes van gevaar" (88). Met voete "kloppend van pyn" en in die grootste eensaamheid steier hy soms voort, ondersteun deur slegs die herinnering aan die versorging deur die natuur, "die smaak van bessies en veldkruie, 'n hele somer lank" (88). Ná'n vreesaanjaende storm tydens die skeepvaart onderweg na sy pa se broer, Korban, put Eron hoop uit "die wit vredesvlag" van 'n meeu bokant die maste", die eerste seemeeu in ses dae (103).

Deur die uitbeelding van hierdie storm word korte mette gemaak van die illusie van die mens se gesag oor niemenslike en nielewende dinge. Die matrose het "verwoed probeer om die seile in te bind en beheer te neem oor wind en weer, maar dit het gelyk of hulle 'n ondier onder 'n laken wou vastem" (103). Met dieselfde onbetwiste gesag as waarmee die storm losgebreek het, "so onverwags as wat dit gekom het", het die storm "bo hulle koppe verbygewaai" (103).

Korban, die oom wat op die verdere reis as mentor vir Eron optree, leef asof volgens volle insig omtrent die dinamiese en handelende aard van die materiële magte en invloede rondom die mens. Met die doel om die seun voor te berei op die res van sy reis, stel hy hom bloot aan die biografieë van die sestiende-eeuse ontdekkingsreisiger en botanis Clover. Dis boeke waarin Eron wêrelddele vind "waar nuwe biosfere ontdek is", hy leer omtrent voëlspesies en woestyne, kosmologie en fisika (120). Deur hierdie blootstelling aan teoretiese aspekte omtrent die natuurwêreld, en deur praktiese bewyse van die effek en invloed van materie uit die sfeer van die niemenslike, word Eron gelei om die natuur te respekteer as 'n aktiewe rolspeler in sy omstandighede.

Bogenoemde idee word baie sterk uitgebou in die roman: die natuur, in samewerking met die bo-natuur, het soms 'n ingrypende effek op die menslike gebeure. Die natuur kan byvoorbeeld in weerwraak op mense se verwoesting en hebsug reageer. So heers daar 'n "onvoorspelbare oorlog tussen walvisjagter en wildernis" op Die Eiland van die Ure, waar walvisskepe halfjaarliks aandoen om voorrade aan te vul:

Soms, so het Clover in sy opskrywings beweer, het die natuur geantwoord met wraakaanvalle. Onder die walvisbote het riviere van vuur gevloei en uitgebreek in verwoede vlamme. Wanneer puinsteen uit die see spat, was die hawe en huise en alles daarrondom binne 'n oogwink 'n blink begraafplaas. Hoe dikwels dit gebeur, kon niemand voorspel nie. Dalk in hierdie leeftyd, dalk eers in die leeftyd van die tiende nageslag. (174)

Op Eziovlei neem Eron die samevloeiing van die ritmes van mens en natuur waar. Ná weke van winterstorms is die strand platgevee en die seewater stroom land-in. Die water borrel al hewiger op in die leivore en damme, sodat die stroompies spoedig in beweging kom en in riviere verander. Een oggend, toe Eron by die soldervenster uitkyk, is Korban se tuin heeltemal onder water, die huismeisies gryp wasgoed bymekaar op die oewer en die vissers trek hulle nette en skuite inderhaas uit om te verhoed dat dit wegspoel. Nou neem voëls die gebied in besit: "Vanaf die mere van Oborto het die swanevolk gekom, oor land en see [...], die horisonlyn was gloeiend terwyl dié welberese voëls met vlerke soos die seile van skepe tussen die geraamtetakke van Korban se boord neergestryk het" (124).

Swaanpare herbou hulle neste en talle voëlspesies neem intrek en broei. Eers wanneer die watervlak ná 'n paar maande sak, neem die voëls en hulle kuikens "met'n vlerkgeklap en klankryke 'kloo-kloo-kloo" hulle vertrek en kan die mens weer terug beweeg in die gebiede van die tuine en kus. Die marmerbeelde in Koran se tuin is groen van die slyk en voëlmis; Eron skuur die tuinbeelde, poets die sonwyser met byewas en knap die mure van Korban se werkplek op (124). In die gegewe van die gedeelde lewensfeer van mens en voël is iets herkenbaar van die posthumanistiese beskouing van die mens waarvan die eggo's ook in die sfeer van die materiële ekokritiek opklink. Wolfe (Before the law 34) stel duidelik dat die ondermyning van die menslike ontologie nie die beëindiging van menslike aansprake op die benutting van natuurruimtes en -hulpbronne impliseer nie, maar'n beklemtoning behels van die saambestaan en gesamentlike evolusionêre spiraal van die mens en die biologiese spesies wat die planeet met hom deel. Sy slotsom: "We should read the new category human in terms of co-emergence within a shared field of existence marked by the interdependency of life" (34).

\section{Slot}

In die lig van die positiewe ontvangs van Die Bergengel is 'n literêr-analitiese ondersoek van die roman aangepak. Met behulp van 'n ekokritiese leesstrategie is daarin geslaag om tot die kern van die literêre gehalte daarvan deur te dring.

Eerstens is bevind dat die sfere van kultuur en natuur met die talent van 'n woordmeester geïntegreer word. Daar is vasgestel hoe die poëtiese taal en die trefkrag daarvan funksioneel benut word in die omdop van vasgestel- 
de idees oor die verhouding tussen die menslike en die niemenslike. Deur die spel met taal word 'n konteks van hernude en skerp aandag geskep om oortuigingskrag tot die argument oor die rol en waarde van die natuur en oor die belang van omgewingskwessies toe te voeg. Waar die medium van taal so direk by die doel van die uitbou van die ekokritiese diskoers ingevleg word, word die potensiaal van letterkunde tot die byeenbring van die verwyderd gewaande sfere van kultuur en natuur gedemonstreer. Die Bergengel is 'n sterk en geloofwaardige stem in die diskoers oor herintegrasie wat 'n kernkomponent in Zapf se beskouing van letterkunde as kulturele ekologie vorm.

Die ekologiese funksie van letterkunde as herstrukturerende en herorganiserende krag het uit die romanontleding duidelik geword. In die ondersoek na die besonderhede omtrent hierdie ekologiese krag wat in Die Bergengel opgesluit lê, is bevind dat 'n koersverandering ten opsigte van die heersende mensgerigte beskouing van natuuren omgewingsake voorgestaan word. Daar klink 'n oortuigende téénstem op teenoor tematiese gegewens wat 'n antroposentriese houding belig. Groter waarhede ten opsigte van die natuur se aktiewe rol van beïnvloeding van die mens kom onder die aandag en die opheffing van die mens se veronderstelde sentrale posisie, wat in bepaalde verhaalgebeure plaasvind, versterk gesonde nuwe perspektiewe. Die Bergengel herinner ons aan die kosbaarheid van 'n gedeelde bestaansfeer, aan die kompleksiteite van die interafhanklike saambestaan met die niemenslike en aan 'n noodsaaklike verbintenis van respek as teenvoeter vir omgewingsverwoesting en menslike uitbuiting van reeds karige hulpbronne.

\section{Aantekeninge}

1. Spekulatiewe fiksie word dikwels as 'n breë term ingespan om fiksie met bonatuurlike, futuristiese of fantasie-elemente te omskryf (Steenkamp, "Bergengel"). In hierdie sin is Die Bergengel wel spekulatief: die verhaal bevel beide bonatuurlike en fantasie-elemente. Lem (144) beklemtoon egter dat die grense tussen wetenskapfiksie, spekulatiewe fiksie en fantasie soms vaag is: "Most of these subgenres are narratives that elaborate some imaginative or fantastic premise, perhaps involving a postulated future society, or travels between different worlds". Die allegorie kan beskryf word as 'n verhaal waarin die algemene voorgestel word deur middel van die besondere. Die karakters en hulle handelinge funksioneer in 'n allegorie op twee vlakke: hulle bestaan op 'n eerste, konkrete verhaalvlak, maar wys ook heen na 'n stel gebeure of 'n stel morele, geestelike of psigologiese konsepte/idees agter die verhaal (Malan). Die magiese realisme is 'n verskynsel in literêre werk waar die konkreet-reële aspekte soos karakters, ruimte en gebeure geplaas word teen die agtergrond van die magiese of ook die metafisiese. Die magiese realisme is gebaseer op die gedagte dat die mens (en so die karakter in die literêre werk) bande het met 'n bosinlike bestaan, selfs met'n oerbestaan (Van der Elst). Die Bildungsroman word deur English Oxford Living Dictionaries beskryf as 'n verhaal oor 'n jong protagonis se reis deur sy vormingsjare tot volwassenheid, uitgebeeld met aandag aan verskeie aspekte van sy ontwikkeling en volwassewording.

2. Vir lesers wat belangstel in die geskiedenis van fantasie en wetenskapfiksie in Afrikaans, is die webwerf www.afrikafiksie. com 'n nuttige bron van inligting. Hier word 'n volledige rekord van Afrikaanse fantasie-en WF-publikasies verskaf en gereeld opgedateer.

3. Wat die terrein van die Afrikaanse literatuurteorie en -kritiek betref, word die invloed van die nuwe materialisme op die ekokritiese lees van tekste deur die navorsing van ondersoekers soos Susan Smith en Susan Meyer erken (Smith, "Ekokritiek en die nuwe materialisme" en "Plek as liggaam"; S. Meyer, "Die allesomvattende materiële dimensie van ons bestaan: aspekte van die nuwe materialisme in Vuurklip van Marié Heese" en "Mens-plantverbintenisse in Die sideboard van Simon Bruinders").

4. Die teorie van die objekgeoriënteerde ontologie is geskep deur Graham Harman, maar goed uiteengesit en ook verder ontwikkel deur Timothy Morton, onder andere in Ecology Without Nature (2007) en The Ecological Thought (2010).

Geraadpleegde bronne

Alaimo, S. \& S. Hekman. "Introduction: Emerging models of materiality in feminist theory." Material Feminisms. Reds. S. Alaimo \& S. Hekman. Indiana U P, 2008, pp. 1-11.

Amid, J. "Roman verhef woord tot heiligdom." Netwerk 24: Boeke/Fiksie. 4 Jul. 2017. https://www.netwerk24.com/Vermaak/ Boeke/roman-verhef-woord-tot-heiligdom-20170702. Geraadpleeg 12 Apr. 2018.

Bennett. J. Vibrant Matter: A Political Ecology of Things. Duke U P, 2010.

Buell, L. The Environmental Imagination: Thoreau, Nature Writing, and the Formation of American Culture. Harvard U P, 1995.

Buell, L., Heise, U. K. \& K. Thornber, "Literature and environment.” Annual Review of Environment and Resources vol. 36, 2011, pp. 417-40.

Childs, P. \& R. Fowler. The Routledge Dictionary of Literary Terms. Routledge, 2009.

Coole, D. H. \& S. Frost. "Introduction." New Materialisms: Ontology, Agency, and Politics. Reds. D. H. Coole \&\& S. Frost. Duke U P, 2010, pp. 1-23.

English Oxford Living Dictionaries. Lexico. "Definition of Bildungsroman.” 2018. https://www.lexico.com/en/definition/ bildungsroman. Geraadpleeg 19 Jun. 2019.

Fiedorczuk, J. "The problems of environmental criticism: An interview with Lawrence Buell." Polish Journal for American Studies vol. 5, 2011, pp. 7-13.

Gifford, T. "Recent critiques of ecocriticism." New Formations vol. 64, 2008, pp.15-24.

Glotfelty, C. "Introduction." The Ecocriticism Reader: Landmarks in Literary Ecology. Reds. C. Glotfelty \& H. Fromm. U of Georgia P, 1996, pp. xv-xxxvii.

Lem, S. Microworlds: Writings on Science Fiction and Fantasy. Harcourt Brace \& Jovanovich, 1984. 
Malan, R. “Allegorie." Literêre terme en teorië. http://www.literaryterminology.com/index.php/categories/9-allegorie. Geraadpleeg 14 Mei 2018.

Meyer, N. “Die Bergengel: 'n Onderhoud met Carina Stander.” LitNet Akademies. 10 Jul. 2017. https://www.litnet.co.za/diebergengel-n-onderhoud-met-carina-stander/. Geraadpleeg 14 Mei 2018.

Meyer, S. "Die allesomvattende materiële dimensie van ons bestaan: aspekte van die nuwe materialisme in Vuurklip van Marié Heese." LitNet Akademies vol. 12, no. 2, 2015, pp. 69-89. https://www.litnet.co.za/die-allesomvattende-materiele-dimensievan-ons-bestaan-aspekte-van-die-nuwe-materialisme-in-vuurklip-van-marie-heese/.

"Mens-plantverbintenisse in Die sideboard van Simon Bruinders." LitNet Akademies vol. 14, no. 1, 2017, pp. 1-26. https:// www.litnet.co.za/mens-plant-verbintenisse-die-sideboard-2014-van-simon-bruinders/.

Morton, T. "Here comes everything. The promise of object-orientated ontology." Qui Parle vol. 19, no. 2, 2011, pp. $163-90$.

Myburg, J. "Boek van die maand: 'Die Bergengel': Verbeelding wat deurgaans betower." Maroelamedia. 17 Augustus 2017. https://maroelamedia.co.za/afrikaans/boeke/boek-van-die-maand-resensie-die-bergengel-verbeelding-wat-deurgaansbetower/. Geraadpleeg 14 Mei 2018.

Oppermann, S. "Feminist ecocriticism: the new ecofeminist settlement." Feminismo/s vol. 22, 2013, pp. 65-88.

"From Material to Posthuman Ecocriticism: Hybridity, Stories, Natures". Handbook of Ecocriticism and Cultural Ecology. Red. H. Zapf. De Gruyter Mouton, 2016, pp. 243-94.

Salovaara, H. “Book review: Hubert Zapf, Literature as Cultural Ecology: Sustainable Texts.” Ecozon@ vol 8, no. 1, 2017, pp. 222-5.

Smith, S. "Ekokritiek en die nuwe materialisme. 'n Ondersoek na die nuwe materialisme in enkele gedigte van Johann Lodewyk Marais uit die bundel In die bloute (2012)." LitNet Akademies vol. 11, no. 2, 2014, pp. 749-74. https://www.litnet. co.za/ekokritiek-en-die-nuwe-materialisme-n-ondersoek-na-die-nuwe-materialisme-in-enkele-gedigte/.

. "Plek as liggaam en liggaam as plek. Tendense van die nuwe materialisme en interaksie tussen mens en plek in enkele tekste uit Verweerskrif (2006) van Antjie Krog." LitNet Akademies vol. 12, no. 2, 2015, pp. 1-24. https://www.litnet.co.za/ plek-as-liggaam-en-liggaam-as-plek-tendense-van-die-nuwe-materialisme/.

Stander, C. Die Bergengel. Protea, 2017.

.Die Bergengel: 'n Onderhoud met Carina Stander." LitNet Akademies. 10 Jul. 2017. https://www.litnet.co.za/diebergengel-n-onderhoud-met-carina-stander/. Geraadpleeg 14 Mei 2018.

Steenkamp. E. "Die Bergengel deur Carina Stander: 'n LitNet Akademies resensie-essay.” LitNet Akademies. 14 Sep. 2017. https:/www.litnet.co.za/die-bergengel-deur-carina-stander-litnet-akademies-resensie-essay. Geraadpleeg 12 Apr. 2018. . "Koors deur Deon Meyer: 'n LitNet Akademies resensie-essay." LitNet Akademies. 27 Apr. 2017. https://www.litnet.co.za/ koors-deur-deon-meyer-n-resensie-essay/. Geraadpleeg 18 Mei 2018.

Van der Elst, J. "Magiese realisme”. Literêre terme en teorieë. http://www.literaryterminology.com/index.php/20-m/116-magieserealisme. Geraadpleeg 14 Mei 2018.

Wolfe, C. Before the Law: Humans and Other Animals in a Biopolitical Frame. U of Chicago P, 2013. Critical Environments: Postmodern Theory and the Pragmatics of the "Outside". U of Minnesota P, 1998.

$\overrightarrow{Z a p f}$, H. Literature as Cultural Ecology: Sustainable Texts. Bloomsbury Academic, 2016.

"The state of ecocriticism and the function of literature as cultural ecology." Nature in Literary and Cultural Studies.

Transatlantic Conversations on Ecocriticism. Reds. C. Gersdorf \& S. Mayer. Rodopi, 2006, pp. 50-69. 